\title{
Selective Spinal Anesthesia in a Patient with Low Ejection Fraction Who Underwent Emergent Below-Knee Amputation in a Resource-Constrained Setting
}

This article was published in the following Dove Press journal:

Local and Regional Anesthesia

Hailemariam Mulugeta (D) Abebayehu Zemedkun (D) Hailemariam Getachew

Department of Anesthesiology, College of Medicine and Health Science, Dilla University, Dilla, Ethiopia
Correspondence: Hailemariam Mulugeta Department of Anesthesiology, College of Medicine and Health Science, Dilla University, PO Box 4/9//3, Dilla, Ethiopia Tel +25I 9704 I 5208

Fax +25I 46 33I 0894

Email hmerry1990@gmail.com

\begin{abstract}
Patients with congestive heart failure have a high risk of perioperative major adverse cardiac events and death. The major perioperative goal of management in patients with low ejection fraction is maintaining hemodynamic stability. Evidence is scarce on the safety of a certain anesthetic technique for patients with heart failure. In this report, we present a 48-year-old man with ischemic dilated cardiomyopathy and low-output congestive heart failure (estimated ejection fraction of $27 \%$ ) who underwent emergent below-knee amputation under selective spinal anesthesia without any apparent complications. We believe that selective spinal anesthesia can be a useful alternative anesthetic technique in patients with low ejection fraction undergoing emergent lower limb surgery. We showed evidencebased and customized anesthetic management of a high-risk patient with the available equipment and resources. This report will hopefully show the contextual challenges of the perioperative care of critically ill patients in resource-constrained settings.
\end{abstract}

Keywords: congestive heart failure, low ejection fraction, dilated cardiomyopathy, neuraxial anesthesia, cardiovascular effects, spinal anesthesia spread, factors

\section{Introduction}

Congestive heart failure (CHF) is a major health burden, affecting 40 million people globally, and dilated cardiomyopathy (DCM) is one of its leading causes. $^{1,2}$ The number of patients with CHF presenting for surgery continues to rise, and anesthesiologists are responsible to provide safe perioperative care for patients with low ejection fraction (EF). ${ }^{3}$ The risk of perioperative mortality and morbidity in patients with CHF is considerably high demonstrating the need for optimal perioperative management in these patients. ${ }^{4,5}$

Anesthetic goals in patients with low EF include maintaining forward flow and promoting inotropy. Pharmacologic agents, such as beta-blockers may be used perioperatively to achieve this goal. Nesiritide and levosimendan are popular new agents to optimize patients with acute CHF. Patients who are unresponsive to pharmacologic therapy will require assist devices, and others may even need extracorporeal membrane oxygenation. ${ }^{3,6}$

There is a paucity of evidence on the safety of a certain anesthetic technique for patients with $\mathrm{CHF}^{5}$ The key point is to avoid myocardial depression, maintain 
hemodynamic stability, and meeting the requirements of surgery. ${ }^{7}$ In this report, we present perioperative management of a patient with uncontrolled type II diabetes mellitus (DM) and CHF secondary to ischemic DCM with an estimated $\mathrm{EF}$ of $27 \%$, and who had undergone emergent below-knee amputation under selective spinal anesthesia with a mixture of low dose bupivacaine, fentanyl, and dexmedetomidine. Our intention was to maintain hemodynamic stability and minimize other anesthesia-related perioperative side effects by controlling the spread of the spinal block so that only the nerve roots supplying the site of surgery are affected. This manuscript adheres to the applicable CARE case report guideline.

\section{Case Description}

A 48-year-old man (80 kg, $177 \mathrm{~cm}$, and ASA PS-IV) was scheduled for emergent below-knee amputation after he was found to have left lower limb diabetic foot ulcer associated with whole foot gangrene and osteomyelitis. His medical history was significant for uncontrolled type II DM and New York Heart Association class IV stage C CHF secondary to ischemic 4-chamber DCM. Electrocardiography analysis showed sinus tachycardia, left axis deviation, left ventricular hypertrophy, and inferior myocardial infarction. Bedside examination of transthoracic echocardiography prior to surgery estimated left ventricular EF of $27 \%$ and noted minimal tricuspid regurgitation. Posteroanterior chest radiography revealed cardiomegaly with signs of left chamber enlargement and grade-2 pulmonary edema. Bilateral lower limb arterial duplex ultrasonography was suggestive of peripheral arterial disease with mild atherosclerotic changes. Other organ function and biochemical disturbances included mild hypokalemia, hypernatremia, hyperchloremia, hyperglycemia, and leukocytosis (Table 1). His medications on admission included NPH insulin, aspirin, atorvastatin, furosemide, and metoprolol. We estimated his subjective metabolic equivalent of tasks $\leq 4$, revised cardiac risk index (Lee criteria) of $>11 \%$, and glomerular filtration rate of $21,518 \mathrm{~mL} / \mathrm{min} / 1.73 \mathrm{~m}^{2}$.

At admission to the operation theatre, he was diaphoretic with cold and clammy hands and feet. After informed consent, he was taken to the operating room where standard monitors were placed, and supplemental oxygen was administered via nasal cannula. A urinary catheter was placed to monitor urine output. The patient was then placed in a sitting position for spinal anesthetic administration.
Table I Summary of Preoperative Laboratory Results

\begin{tabular}{|c|c|c|c|}
\hline Test Name & Result $^{a}$ & Reference & $\begin{array}{l}\text { Unit of } \\
\text { Measure }\end{array}$ \\
\hline WBC & 19.5 & $3.6-10.2$ & $\times 10^{3}$ cells $/ \mathrm{L}$ \\
\hline RBC & 6.25 & $4.06-5.63$ & $\times 10^{6} \mathrm{cell} / \mathrm{L}$ \\
\hline Hematocrit & 39.0 & $36.7-47.1$ & $\%$ \\
\hline Hemoglobin & 13.1 & $12.5-16.3$ & $\mathrm{~g} / \mathrm{dL}$ \\
\hline Platelet count & 188 & $152-348$ & $\times 10^{3}$ cells $/ \mu \mathrm{L}$ \\
\hline ESR & 13 & $0-30$ & $\mathrm{~mm} /$ hour \\
\hline $\mathrm{HgbAIC}$ & II.I & $4.0-7.0$ & $\%$ \\
\hline Rapid Blood Sugar & 235 & $80-140$ & $\mathrm{mg} / \mathrm{dL}$ \\
\hline $\mathrm{K}^{+}$ & 3.3 & $3.5-5.1$ & $\mathrm{mmol} / \mathrm{L}$ \\
\hline $\mathrm{Na}^{+}$ & 182.3 & $135.0-155.0$ & $\mathrm{mmol} / \mathrm{L}$ \\
\hline $\mathrm{Cl}^{-}$ & 113.2 & $98.0-111.0$ & $\mathrm{mmol} / \mathrm{L}$ \\
\hline Blood urea nitrogen & 46 & $8-25$ & $\mathrm{mg} / \mathrm{dL}$ \\
\hline Creatinine & 0.86 & $0.7-1.2$ & $\mathrm{mg} / \mathrm{dL}$ \\
\hline Urine Glucose (UGLU) & +2 & & $\mathrm{mg} / \mathrm{dL}$ \\
\hline $\begin{array}{l}\text { Urine protein (UR } \\
\text { PRO) }\end{array}$ & +1 & Negative & $\mathrm{mg} / \mathrm{dL}$ \\
\hline $\begin{array}{l}\text { Urine red blood cell } \\
\text { (BLD) }\end{array}$ & +1 & $<3$ & Cells/HPF \\
\hline Urine WBC & $5-10$ & $\leq 4$ & Cells/HPF \\
\hline Ketone & Negative & & \\
\hline $\begin{array}{l}\text { High sensitive troponin } \\
\text { test }\end{array}$ & 0.104 & $\leq 14$ & $\mathrm{ng} / \mathrm{L}$ \\
\hline
\end{tabular}

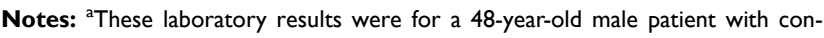
gestive heart failure, and type 2 diabetes mellitus who was admitted to operation theatre to undergo below-knee amputation for a diabetic foot ulcer under selective spinal anesthesia.

Abbreviations: WBC, white blood cell count; RBC, red blood cell count; ESR, erythrocyte sedimentation rate; HgbAIC, glycosylated hemoglobin; HPF, high power field.

The spinal block was performed by a consultant anesthetist between the level of L3 and L4 interspace using the midline approach. The skin was anesthetized with $3 \mathrm{~mL}$ of lidocaine $2 \%$, and a $24-\mathrm{G}$ Quincke spinal needle was used to administer a mixture of heavy bupivacaine $7.5 \mathrm{mg}$ in $1.5 \mathrm{~mL}$ volume (BUPICAN"T HEAVY, $20 \mathrm{mg} / 4 \mathrm{~mL}$ ampule, Baxter Pharmaceuticals, India), dexmedetomidine $4 \mu \mathrm{g}$ in $1 \mathrm{~mL}$ volume (Precedex ${ }^{\mathrm{TM}}, 400 \mu \mathrm{g} / 100 \mathrm{~mL}$ vial, Hospira, USA), and fentanyl $25 \mu \mathrm{g}$ in $0.5 \mathrm{~mL}$ volume (Fentanyl®, $100 \mu \mathrm{g} /$ $2 \mathrm{~mL}$ ampule, Janssen-Cilag Pharmaceutica, Germany). Phenylephrine, $50 \mu \mathrm{g}$, was administered intravenously, just before the subarachnoid block, as prophylaxis to postspinal hypotension. Immediately after the intrathecal injection, the patient was placed in the lateral position for 15 minutes, with the operative side down and the head $15^{\circ}$ up. Then, he was turned supine and properly positioned for surgery. The sensory assessment revealed a loss of pinprick sensation to the level of T11 dermatomes and extending to both posteriorly and anteriorly. 
Heart rate, oxygen saturation, and blood pressure were recorded before spinal anesthesia (baseline: mean blood pressure, MAP $87 \mathrm{mmHg}$; heart rate, HR $92 \mathrm{bpm}$; and $\mathrm{S}_{\mathrm{p}}$ $\mathrm{O} 2$ at room air, $90 \%$ ), just after spinal anesthesia, and then every 5 minutes till the end of surgery. Hemodynamic stability was maintained throughout surgery (ie, MAP, 75-92 mmHg; HR, 80-100 bpm; and average hourly urine output, $50 \mathrm{~mL}$ ). His $\mathrm{SpO}_{2}$ and skin temperature were maintained between $95 \%$ and $99 \%$, and $36.0-36.8{ }^{\circ} \mathrm{C}$, respectively. The rapid blood sugar test result at admission to operation theatre was $235 \mathrm{mg} / \mathrm{dL}$. Intravenous regular insulin infusion (1unit/hour) was administered over an hour of the procedure, and the serum glycemic level was kept below $180 \mathrm{mg} / \mathrm{dL}$. The surgical procedure was done by an orthopedic surgeon with 6 years of experience and lasted 80 minutes without any apparent complications. He received a total of $950 \mathrm{~mL}$ crystalloid and $350 \mathrm{~mL}$ packed red blood cells (PRBCs). The total estimated blood loss (EBL) was $350 \mathrm{~mL}$, and the urine output was $150 \mathrm{~mL}$. The patient was transferred to the postanesthesia care unit for further monitoring and then transported to the medical ward. He did not experience any side effects of perioperative therapy, including nausea, vomiting, pruritus, hypotension, or postdural puncture headache during his postoperative course. Postoperative laboratory exam on day one revealed hemoglobin, $12.1 \mathrm{~g} / \mathrm{dL}$; hematocrit, $35 \%$; platelet, $185 \times 10^{3}$ cells/ $\mu \mathrm{L}$; white blood cells, $15.6 \times 10^{3}$ cells $/ \mathrm{L}$; creatinine, $0.97 \mathrm{mg} / \mathrm{dL}$; blood urea nitrogen, $42 \mathrm{mg} / \mathrm{dL} ; \mathrm{K}^{+}, 3.7$ $\mathrm{mmol} / \mathrm{L} ; \mathrm{Na}^{+}, 160 \mathrm{mmol} / \mathrm{L}$; and $\mathrm{Cl}^{-}, 112.8 \mathrm{mmol} / \mathrm{dL}$. He was discharged home on postoperative day 8 after the medical conditions were optimized.

\section{Discussion}

Heart failure is a high-risk disease with considerable perioperative morbidity and mortality demonstrating the need for careful assessment, optimization, and anesthesia planning for patients undergoing cardiac or noncardiac surgery. ${ }^{5,8}$ Recent advances in cardiovascular anesthesia comprise advanced use of monitors, assist devices, and customized pharmacologic management. ${ }^{8}$ When there is evidence of acute CHF in patients admitted for emergent surgery, the procedure should be postponed whenever possible until the cardiac function is compensated and hemodynamic stability is achieved. ${ }^{4}$ On the other hand, there might be a time when patients are admitted on emergent basis and the risk of postponing the surgical procedure is overriding. Likewise, we encountered a case in which a patient with ischemic DCM with low-output CHF admitted for emergent below-knee amputation for a lifethreatening diabetic foot ulcer. The physical examination findings suggesting a low-output state preoperatively were inconclusive to presume that they were from preexisting heart failure and/or sepsis. Besides, one could argue that the patient should have been delayed until the blood sugar level is controlled. However, the medical team was not only concerned about a possible acute exacerbation of cardiopulmonary decompensation but also they were unable to control blood sugar associated with systemic septicemia.

There is a scarcity of data on the use of a certain anesthetic technique for patients with reduced $\mathrm{EF}^{5,6}$ In any surgical procedure involving low EF, maintaining hemodynamic stability, and even intraoperative survival become challenging issues. Efforts should be made to prevent intraoperative arterial hypotension and an inappropriately deep anesthesia level. ${ }^{6,7}$

The provision of anesthesia for patients with DCM undergoing non-cardiac surgery is challenging and is associated with high perioperative morbidity and mortality. The ventricular function, degree of myocardial fibrosis, and resting heart rate can affect survival rates. The goals of perioperative management in these sets of patients include focused preoperative assessment, close perioperative monitoring, suitable anesthetic, and maintaining hemodynamic stability. A thoracic epidural blockade may reverse myocardial fibrosis and improve ventricular function. ${ }^{7}$ A retrospective study by Ituk et al also examined the successful use of combined spinal-epidural, epidural and general anesthesia in parturient with DCM. ${ }^{9}$ In our case, we dictated that the patient would have an elevated risk of perioperative major adverse cardiac event, with an estimated revised cardiac risk index for noncardiac surgery of $>11 \%$, or death due to the combined cardiac and endocrine comorbidity. A team decision was made to perform the surgical procedure under SSA. Although the changes in outcome related to neuraxial anesthetic techniques in patients with cardiac disease are not clearly known, ${ }^{6}$ epidural anesthesia may be advocated by many clinicians to achieve a more gradual and hemodynamically stable anesthetic. However, we did not have the privilege to provide it due to resource limitations.

Selective spinal anesthesia (also known as modified spinal anesthesia) can be achieved by using a reduced dose of local anesthetic plus adjuvants and by adopting maneuvers to control the spread of the block so that only the nerve roots supplying specific area are affected. 
Unilateral lower limb block, lower torso block and saddle block are some of its variants. The technique is popular in day surgery, intending to incorporate patients with comorbidities who would otherwise be excluded. ${ }^{10}$

There is compelling evidence that adding adjuvants, such as opioids and $\alpha-2$ agonists to a reduced dose of an intrathecal local anesthetics (LA) can decrease LA related adverse effects and prolong postoperative analgesia without compromising intraoperative anesthesia. ${ }^{11-13}$ Having these experiences in mind, we conducted a modified spinal block using a mixture of low dose heavy bupivacaine $(7.5 \mathrm{mg})$, dexmedetomidine $(4 \mu \mathrm{g})$ and fentanyl $(25 \mu \mathrm{g})$.

Dexmedetomidine, a highly selective $\alpha-2$ receptor agonist, is found to have antinociceptive action when administered intrathecally. It was associated with prolonged motor and sensory spinal block and reduced the demand for rescue postoperative analgesics. ${ }^{14}$ Fentanyl, on the other hand, is a highly lipophilic, potent $\mu$-opioid receptor agonist that may fasten the onset of spinal block, prolong the duration of sensory block and reduce the analgesic requirement in the early postoperative period following its use as an additive to bupivacaine spinal anesthesia. ${ }^{15}$ It is a daily clinical practice to use dexmedetomidine and fentanyl for spinal anesthesia without approval. Besides, the United States Food and Drug Administration recommends clinicians may prescribe a drug for off-label use when they determine that it is medically appropriate for their patients. ${ }^{16}$ In our case, we used dexmedetomidinefentanyl admixture with our prior knowledge that adding different adjuvants, with a varied mechanism of action, together would fasten the onset and quality of spinal anesthesia and decrease the dose requirement of LAs.

There is an increased demand for spinal anesthesia in high-risk patients with comorbidity dictating the continual search for drug combinations to improve perioperative anesthesia and analgesia while limiting side effects. The addition of dexmedetomidine plus fentanyl to bupivacaine intrathecally not only reduced the dose of an intrathecal LA requirement but also enhanced the duration of postoperative analgesia, and was not associated with hemodynamic instability. ${ }^{11,13}$ On the other hand, dexmedetomidine added to hyperbaric bupivacaine intrathecally has a dosedependent $(5 \mu \mathrm{g}$ versus $10 \mu \mathrm{g})$ favorable effect on the onset and regression of sensory and motor block. ${ }^{17}$

Spinal anesthesia-induced hypotension is one of the commonest immediate complications after the block due to arterial and venous vasodilatation resulting from the sympathetic block along with a paradoxical activation of cardio-inhibitory receptors. Fluid preloading with colloids or co-loading with crystalloid (or colloid) effectively reduces the incidence and severity of arterial hypotension. Phenylephrine or noradrenaline can be used to treat SAIH and as a prophylactic administration. ${ }^{18}$ In our patient, the goal was to maintain the patient's baseline mean blood pressure $(87 \mathrm{mmHg})$ by applying the principles of unilateral SSA, and we were successful. We did not intend to preload or co-load him for the spinal block with a fear of acute exacerbation of CHF. Only a single bolus of phenylephrine was administered as prophylaxis to postspinal hypotension just before the spinal block.

Our fluid management was empirical since we did not monitor the adequacy of organ perfusion directly. A slow transfusion of packed red blood cells diluted with crystalloids was started early after skin incision. The rate of infusions was adjusted based on the estimated blood loss, blood pressure, and urine output. Although our stated goal was euvolemia, one could claim that the patient was overresuscitated by the end of the procedure, with $950 \mathrm{~mL}$ crystalloid and $350 \mathrm{~mL}$ PRBCs in as opposed to $350 \mathrm{~mL}$ blood loss and $150 \mathrm{~mL}$ urine output. However, we were concerned that insufficient preload due to hypovolemia could worsen his cardiac output. Moreover, any decrement in arterial blood oxygen was doubtful to be compensated by an increase in cardiac output since our patient had a negligible cardiac reserve.

Invasive blood pressure monitoring and goal-directed fluid therapy has been recommended in patients with CHF. The use of perioperative transthoracic or transesophageal echocardiography has been strongly recommended in patients at risk for acute exacerbation of $\mathrm{CHF}^{5,6}$ To date, the importance of filling pressure monitoring (central venous pressure and pulmonary artery pressure) is not well known but it was advised in patients with severe pulmonary hypertension and at risk of acute exacerbation of left ventricular dysfunction. ${ }^{5}$ Invasive hemodynamic monitors were not used in our case due to resource constraints. Continuous electrocardiography (ECG) monitoring was used to detect ST-segment changes and identify the presence of myocardial ischemia. However, it is not clear if ECG monitoring is adequately sensitive to identify patients with myocardial ischemia. ${ }^{6}$

\section{Conclusion}

We present a case in which a patient with low EF underwent emergent below-knee amputation under modified spinal anesthesia. We claim that the successful conduct 
of anesthesia, in this case, relies on a widespread appreciation of the clinical significance of adjuvants, such as opioids and $\alpha-2$ agonists, mechanism of action of LAs, and adoption of the maneuvers to control the spread of the spinal block. We showed evidence-based anesthetic management of a high-risk patient with the available equipment and drugs in a low resource setting. We hope our report would be a very valuable educational experience showing the contextual challenges of perioperative care of critically ill patients in resource-constrained settings. We believe that selective spinal anesthesia can be a useful alternative anesthetic technique in patients with lowoutput heart failure undergoing emergent lower limb surgery. However, more evidence is required to determine the optimal combination of LAs and adjuvants for orthopedic procedures in high-risk patients.

\section{Abbreviations}

ASA PS-IV, American Society of Anesthesiologists Physical Status Class IV; CARE, CAse REport; CHF, Congestive Heart Failure; DCM, Cardiomyopathy; DM, Diabetes Mellitus; ECG, Continuous Electrocardiography; EF, Ejection Fraction; HR, Heart Rate; L3/L4, Third/Fourth Lumbar vertebrae; LA, Local Anesthetic; MAP, Mean Blood Pressure, NPH, Neutral Protamine Hagedorn; PRBCs, Packed Red Blood Cells; $\mathrm{S}_{\mathrm{p}} \mathrm{O}_{2}$, Peripheral Oxygen Saturation; SSA, Selective Spinal Anesthesia.

\section{Ethical Approval and Patient Consent}

This case report has been exempted by the Institutional Review Board of Dilla University College of Medicine and Health Science from requiring ethical approval. Informed written consent was obtained from the patient to participate as well as to publish the data.

\section{Funding}

There was no any source of funding or financial support for this report.

\section{Disclosure}

The authors report no conflicts of interest in this work.

\section{References}

1. Tayal U, Prasad S, Cook SA. Genetics and genomics of dilated cardiomyopathy and systolic heart failure. Genome Med. 2017;9 (1):20. doi:10.1186/s13073-017-0410-8
2. Caviedes Bottner P, Córdova Fernández T, Larraín Valenzuela M, Cruces Romero Presentación de Casos Clínicos P. Dilated cardiomyopathy and severe heart failure. An update for pediatricians. Arch Argent Pediatr. 2018;116(3):e421-e428. doi:10.5546/aap.2018.eng.e421

3. Chua JH, Nguyen R. Anesthetic management of the patient with low ejection fraction. Am J Ther. 2015;22(1):73-79. doi:10.1097/ MJT.0b013e31826fc458

4. van Diepen S, Bakal JA, McAlister FA, Ezekowitz JA. Mortality and readmission of patients with heart failure, atrial fibrillation, or coronary artery disease undergoing noncardiac surgery: an analysis of 38 047 patients. Circulation. 2011;124(3):289-296. doi:10.1161/ CIRCULATIONAHA.110.011130

5. Smit-Fun V, Buhre WF. The patient with chronic heart failure undergoing surgery. Curr Opin Anaesthesiol. 2016;29(3):391-396. doi:10.1097/ACO.0000000000000335

6. Kristensen SD, Knuuti J, Saraste A, et al. 2014 ESC/ESA guidelines on non-cardiac surgery: cardiovascular assessment and management: the joint task force on non-cardiac surgery: cardiovascular assessment and management of the European Society of Cardiology (ESC) and the European Society of Anaest. Eur J Anaesthesiol. 2014;31 (10):517-573. doi:10.1097/EJA.0000000000000150

7. Chen C-Q, Wang X, Zhang J, Zhu S-M. Anesthetic management of patients with dilated cardiomyopathy for noncardiac surgery. Eur Rev Med Pharmacol Sci. 2017;21(3):627-634.

8. Henes J, Rosenberger P. Systolic heart failure: diagnosis and therapy. Curr Opin Anaesthesiol. 2016;29(1):55-60. doi:10.1097/ACO.00 00000000000270

9. Ituk US, Habib AS, Polin CM, Allen TK. Anesthetic management and outcomes of parturients with dilated cardiomyopathy in an academic centre. Can J Anaesth. 2015;62(3):278-288. doi:10.1007/ s12630-014-0290-y

10. Watson B, Allen J. Spinal Anaesthesia. In: Smith I, McWhinnie D, Jackson I, editors. Day Case Surgery. 1st ed. New York: Oxford University Press; 2012:79-91.

11. Mazy A, Ghanem MA, Abd Elatif MSE, Basyoni YE. Spinal anesthesia for lengthy lower limb orthopedic surgeries: dexmedetomidine plus fentanyl versus dexmedetomidine. Ain-Shams J Anesthesiol. 2019;11(1):10. doi:10.1186/s42077-019-0024-z

12. Pöpping DM, Elia N, Wenk M, Tramèr MR. Combination of a reduced dose of an intrathecal local anesthetic with a small dose of an opioid: a meta-analysis of randomized trials. Pain. 2013;154 (8):1383-1390. doi:10.1016/j.pain.2013.04.023

13. Megalla S. Adding dexmedetomidine to bupivacaine-fentanyl mixture in high-risk elderly patients undergoing orthopedic surgery: a randomized, double-blind, controlled study. Res Opin Anesth Intensive Care. 2018;5(3):205-212. doi:10.4103/roaic.roaic_39_17

14. Niu X-Y, Ding X-B, Guo T, Chen M-H, Fu S-K, Li Q. Effects of intravenous and intrathecal dexmedetomidine in spinal anesthesia: a meta-analysis. CNS Neurosci Ther. 2013;19(11):897-904. doi:10. $1111 / \mathrm{cns} .12172$

15. Waara-Wolleat KL, Hildebrand KR, Stewart GR. A review of intrathecal fentanyl and sufentanil for the treatment of chronic pain. Pain Med. 2006;7(3):251-259. doi:10.1111/j.1526-4637.2006.00155.x

16. US Food and Drug Administration. Use Caution with Implanted Pumps for Intrathecal Administration of Medicines for Pain Management: FDA Safety Communication. US Food and Drug Administration; November 14, 2018. Available from: https:// www.fda.gov/medical-devices/safety-communications/use-caution -implanted-pumps-intrathecal-administration-medicines-painmanagement-fda-safety. Accessed September 25, 2020.

17. Shaikh SI, Dattatri R. Dexmedetomidine as an adjuvant to hyperbaric spinal bupivacaine for infra-umbilical procedures: a dose related study. Anaesth Pain Intensive Care. 2014;18(2):180-185.

18. Ferré F, Martin C, Bosch L, Kurrek M, Lairez O, Minville V. Control of spinal anesthesia-induced hypotension in adults. Local Reg Anesth. 2020;13:39-46. doi:10.2147/LRA.S240753 


\section{Publish your work in this journal}

Local and Regional Anesthesia is an international, peer-reviewed, open access journal publishing on the development, pharmacology, delivery and targeting and clinical use of local and regional anesthetics and analgesics. The journal welcomes submitted papers covering original research, basic science, clinical studies, reviews \& evaluations, guidelines, expert opinion and commentary, case reports and extended reports. The manuscript management system is completely online and includes a very quick and fair peer-review system which is all easy to use. Visit http://www.dovepress.com/testimonials. php to read real quotes from published authors. 